\title{
FATORES ASSOCIADOS AO ESTRESSE E COPING DA EQUIPE DE ENFERMAGEM DE UTI: UMA REVISÃO INTEGRATIVA*
}

\section{FACTORS ASSOCIATED WITH STRESS AND COPING STRATEGIES OF ICU NURSING TEAM: INTEGRATIVE REVIEW}

\section{FACTORES ASOCIADOS AL ESTRÉS Y COPING DEL EQUIPO DE ENFERMERÍA DE UTI: UNA REVISIÓN INTEGRATIVA}

\author{
Tamara dos Santos Pelegrini Guida ${ }^{1}$, Alexandra Bulgarelli do Nascimento ${ }^{2}$ \\ * Pesquisa apresentada para conclusão do Curso de Pós-Graduação em Enfermagem em Terapia \\ Intensiva Adulto pelo Centro Universitário São Camilo.
}

\begin{abstract}
RESUMO
Objetivo: Integrar o conhecimento produzido sobre os fatores associados ao estresse e coping da equipe de Enfermagem em UTI. Metodologia: Revisão integrativa da literatura que utilizou os descritores: 'esgotamento profissional', 'estresse psicológico', 'unidade de terapia intensiva' e 'enfermagem', nas bases de dados Medline, Lilacs e BDEnf. Resultados: Os 15 artigos demonstraram que os principais estressores foram o 'cuidado à rede de apoio dos pacientes' e o 'lidar com a morte'. Quanto ao coping, poucas estratégias foram mencionadas, destacando-se o 'investimento nas relações interpessoais', uso dos 'serviços de apoio disponibilizados pela liderança' e 'apoio fora do ambiente de trabalho' - através de interações sociais informais, atividade física e lazer. Conclusões: $\mathrm{O}$ estresse em resposta às demandas exigidas pelo trabalho na UTI deve ser investigado e o estabelecimento de ações minimizadoras dos efeitos do estresse são primordiais, visando preservar a saúde do profissional, e a segurança e qualidade do cuidado ao paciente.
\end{abstract}

Descritores: Esgotamento profissional; Estresse psicológico; Unidade de terapia intensiva; Enfermagem.

\begin{abstract}
Objective: Integrating the knowledge produced about the factors associated with stress and coping of nursing staff in the ICU. Methodology: Integrative Literature Review He used the key words: 'burnout', 'psychological stress', 'intensive care unit' and 'nursing' in Medline, Lilacs and BDEnf. Results: The articles 15 showed that the major stressors were' care to the support network of patients' and 'dealing with death'. As for coping, few strategies were mentioned, especially the 'investment in interpersonal relations' use of 'support services provided by the leadership' and 'support outside the working environment' - through informal social interactions, physical activity and leisure. Conclusions: The stress in response to the demands required for the work in the ICU should be investigated and the establishment of mitigating actions the effects of stress are paramount, to preserve the health of the professional, and the safety and quality of patient care.

Descriptors: Burnout, Professional; Stress, Psychological; Intensive Care Units; Nursing.

\footnotetext{
${ }^{1}$ Enfermeira Pós-graduanda em Enfermagem em Terapia Intensiva Adulto do Centro Universitário São Camilo.

${ }^{2}$ Enfermeira. Doutora pela Escola de Enfermagem da USP. Professora do curso de Pós-graduação em Enfermagem em Terapia Intensiva Adulto do Centro Universitário São Camilo.
} 


\section{RESUMEN}

Objetivo: Integrar el conocimiento producido sobre los factores asociados al estrés y coping del equipo de Enfermería en UTI. Metodología: Revisión Integrativa de la Literatura que utilizó los descriptores: "agotamiento profesional", "estrés psicológico", "unidad de terapia intensiva" y "enfermería", en las bases de datos Medline, Lilacs y BDEnf. Resultados: Los 15 artículos demostraron que los principales estresores fueron 'cuidado a la red de apoyo de los pacientes' y el 'tratar con la muerte'. En cuanto al coping, pocas estrategias fueron mencionadas, destacándose la 'inversión en las relaciones interpersonales', además del uso de los 'servicios de apoyo disponibilizados por el liderazgo' y 'apoyo fuera del ambiente de trabajo', a través de interacciones sociales informales, actividad física y el ocio. Conclusiones: El estrés en respuesta a las demandas exigidas por el trabajo en la UTI debe ser investigado y el establecimiento de acciones minimizadoras de los efectos del estrés son primordiales, visando preservar la salud del profesional, y la seguridad y calidad del cuidado al paciente.

Descriptores: Agotamiento Profesional; Estrés Psicológico; Unidades de Cuidados Intensivos; Enfermería.

\section{INTRODUÇÃO}

O trabalho é a atividade central da nossa sociedade, seja por sua natureza econômica ao prover o sustento das pessoas, seja pelo aspecto de reconhecimento social que ele proporciona. Assim ele ganha importância na constituição do modo de vida e, portanto, na saúde física e mental do indivíduo. ${ }^{1}$ De tal modo, fica evidente que quando o trabalhador se adapta à atividade laboral, há favorecimento da sua condição de saúde, oportunizando o controle dos riscos que podem ser devido a aspectos ocupacionais ou não, o que denota a preocupação crescente com a saúde do trabalhador e a segurança no ambiente de trabalho, visando manter a força laboral saudável e produtiva. $^{2}$

A Organização Mundial da Saúde (OMS) tem se empenhado no estudo das doenças relacionadas ao trabalho, que englobam características pessoais do trabalhador e o risco do próprio ambiente de trabalho. ${ }^{2}$

Neste último aspecto, relacionado ao ambiente de trabalho, existem seis grupos de estressores, sendo eles os fatores intrínsecos para o trabalho (condições inadequadas de trabalho, turno, carga horária, contribuições no pagamento, necessidade de viagens, exposição a riscos, incorporação de novas tecnologias e carga quantitativa de tarefas), papéis estressores (papel ambíguo ou conflituoso, grau de responsabilidade para com pessoas e processos), relações no trabalho (relações difíceis com a chefia imediata, colegas, subordinados e clientes), estressores na carreira (falta de desenvolvimento na carreira e insegurança no trabalho devido às reorganizações ou declínio da empresa), estrutura organizacional (estilos de gerenciamento, falta de participação e 
falhas de comunicação) e interface trabalho-casa (dificuldade no manejo dos diferentes papéis sociais que as pessoas possuem, ou seja, no ambiente de trabalho e no ambiente íntimo das suas relações pessoais). ${ }^{3}$

Diante do exposto, fica evidente a necessidade dos gestores se atentarem aos aspectos relacionados ao ambiente de trabalho, assim como ao seu papel frente à minimização do estresse, assim se fazendo pertinente o planejamento e implementação de estratégias que colaborem para a adequação do ambiente ao desempenho do trabalho, detectando e atuando sobre os fatores causadores do estresse, sua prevenção e/ou redução. ${ }^{4}$

Além disso, os níveis de incapacidade temporária, absenteísmo, aposentadorias precoces e riscos à saúde associados à atividade profissional são alarmantes quando relacionados ao estresse ocupacional e à saúde mental dos trabalhadores 5;6, o que traz prejuízos financeiros para a empresa e consequências ao colaborador, sejam no âmbito profissional, pessoal ou social.

Dejours (1992) ${ }^{7}$ refere que o termo estresse foi utilizado pela primeira vez pelo médico canadense Hans Selye, para fazer referência a um conjunto de reações inespecíficas, de ordem química e estrutural apresentada por uma pessoa em situação de tensão. ${ }^{8}$
$\mathrm{O}$ estresse, segundo Lazarus e Launier ${ }^{9}$, é definido como qualquer evento que excede a resistência de um indivíduo, de seu sistema social, ou de suas fontes de adaptação ${ }^{10}$, se configurando como um conjunto de respostas não específicas e que se desenvolve em três fases: fase de alarme - caracterizada por manifestações agudas; fase de resistência - quando as manifestações agudas desaparecem e se estabelece a vivência crônica do estresse; e a fase de exaustão - quando há a volta das reações da fase aguda, conjuntamente à condição crônica do estresse, o que pode causar colapso do organismo, denominado de Síndrome Geral da Adaptação (SGA). ${ }^{11}$

Diante disto, fica evidente que estas fases podem estar presentes no cotidiano dos trabalhadores da saúde, como no caso da equipe de Enfermagem - a qual é constituída por profissionais que têm como objeto, o cuidado da saúde do outro e, concomitantemente, são homens e mulheres com anseios, medos, angústias, entre outros sentimentos decorrentes da vivência humana - o que denota a existência, do que Dejours (1992) denomina de 'psicodinâmica do trabalho', ou seja, a compreensão de que as pessoas devem ser compreendidas em sua totalidade, em detrimento de estarem submetidas ao eixo central societário do trabalho. ${ }^{7}$

Este discernimento é essencial, pois quando excessivo, o estresse produz 
diversas consequências psicológicas e emocionais que resultam em cansaço mental, dificuldade de concentração e perda de memória imediata, bem como crises de ansiedade e de humor ${ }^{12}$ - o que reforça a pertinência de aproximação da temática do estresse e da saúde mental do trabalhador.

Ao se pensar o estresse no âmbito da atuação da Enfermagem, Menzies ${ }^{13}$ - na década de 1960 - já a abordava como uma das profissões mais estressantes ${ }^{10}$, uma vez que os trabalhadores da Enfermagem vivenciam situações de atendimento a pacientes críticos ou instáveis clinicamente 14 - evidenciando que o processo de trabalho de Enfermagem impõe aos profissionais rotinas estressantes e que demandam ser manejadas no dia-a-dia dos estabelecimentos de saúde.

Para além disso, a atuação em Unidade de Terapia Intensiva (UTI), parece trazer outros fatores que podem contribuir para o estresse, como por exemplo, a exposição diária ao ambiente fechado, iluminação artificial, ar condicionado e ruídos contínuos, planta física que pode desfavorecer a visualização dos pacientes críticos, alto grau de exigência técnica e gerencial, deficiências quantitativas e de qualificação dos trabalhadores, incorporação contínua de novas tecnologias, vivência diária com o sofrimento e morte, além da condição clínica crítica dos pacientes, que exige conhecimento sólido para a rápida tomada de decisão, a fim de possibilitar a sobrevida. 10

Para lidar com estas situações de estresse, estratégias de enfrentamento podem ser utilizadas visando resignificar as situações de estresse. Tais estratégias são denominadas de coping, e consistem em ações comportamentais e cognitivas utilizadas para solucionar ou minimizar os efeitos do estresse. O coping pode ser compreendido a partir de dois tipos de estratégias, ou seja, a estratégia centrada no problema, que analisa e define a situação, buscando alternativas para resolvê-la; e a estratégia centrada na emoção, que é utilizada quando o indivíduo percebe que os estressores não podem ser modificados, sendo necessário continuar interagindo com eles. Nesse tipo de estratégia, inclui-se a esquiva, a culpabilidade, o distanciamento, a atenção seletiva, comparações e extração de aspectos positivos de acontecimentos negativos. ${ }^{15}$

O modo com que as estratégias de coping são definidas está determinado, em parte, pelos recursos internos e externos do indivíduo, entre eles, a saúde, crenças, responsabilidade, suporte emocional, habilidades sociais e recursos materiais. ${ }^{16}$ Entretanto, ao adotar o coping, o profissional pode desenvolver comportamentos protetivos, como: ao reforçar os laços familiares, adotar o hábito 
de ler, praticar a sua espiritualidade etc., mas - também - pode se utilizar de respostas prejudiciais, como ao utilizar de comportamentos compulsivos, inclusive, com o uso de substâncias lícitas ou ilícitas, danosos a sua saúde. ${ }^{16}$

A partir do apresentado, este estudo objetivou identificar os fatores associados ao estresse e coping da equipe de Enfermagem de UTI, uma vez que é fundamental que o enfermeiro atuante em UTI, compreenda os fatores associados ao estresse presente neste ambiente assistencial, bem como estimule as práticas de coping, entre os trabalhadores de Enfermagem, visando contribuir para um ambiente de trabalho seguro e que se traduza em bem-estar aos integrantes das equipes de Enfermagem e multiprofissional.

\section{MÉTODO}

Este estudo é do tipo revisão integrativa da literatura, a qual proporciona síntese de conhecimentos e incorporação da aplicabilidade de resultados de estudos significativos na prática ${ }^{17}$, auxiliando o pesquisador a sumarizar literatura teórica e empírica sobre o tema. ${ }^{18}$

Assim, foi utilizada a estratégia metodológica preconizada por Whittemore;
Knafl (2005) ${ }^{19}$, que se propõe a identificar o problema de pesquisa, de forma clara, bem como a etapa de busca na literatura, quando se utilizou de descritores organizados por meio da estratégia de busca: ((esgotamento profissional OR estresse psicológico) AND (unidade de terapia intensiva OR enfermagem)), a qual foi aplicada nas seguintes bases de dados: Medical Literature Analysis and Retrieval System Online (MEDLINE), na Literatura Latino-americana e do Caribe em Ciências da Saúde (LILACS) e na Base de Dados de Enfermagem (BDENF).

Assim, foram selecionados todos os artigos primários, publicados até 31 de dezembro de 2017, nos idiomas português, espanhol ou inglês, e que se apresentaram disponíveis eletronicamente na íntegra e que possuíram adesão ao problema de pesquisa, ou seja, que se propuseram a identificar os fatores associados ao estresse e coping da equipe de Enfermagem de UTI. Inicialmente, ao utilizar a estratégia de busca proposta foram localizados 102 artigos, aos quais foram aplicados os critérios de inclusão, e excluídos as duplicatas, restando 34, cujos títulos e resumos foram lidos, possibilitando a seleção de 15 artigos que apresentaram adesão ao problema de pesquisa (Figura 1). 
Figura 1 - Seleção dos artigos. São Paulo, 2019.

Aplicada a estratégia de busca:

(esgotamento profissional OR estresse psicológico)

120 artigos

AND (unidade de terapia intensiva OR enfermagem)

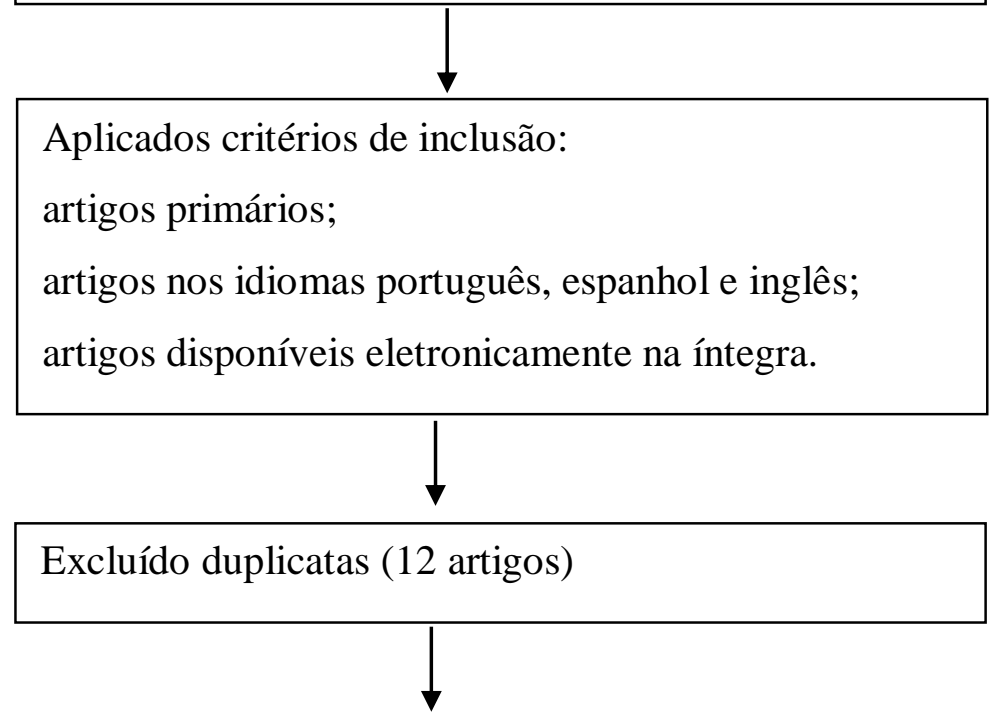

46 artigos

34 artigos

Analisada a adesão dos artigos ao problema de pesquisa, por meio da leitura de títulos e resumos.

15 artigos 
A organização dos dados coletados ocorreu com o auxílio do software Microsoft Excel, no qual foram inseridos os dados dos artigos selecionados quanto ao título, autores, ano e periódicos de publicação, bem como quanto aos participantes dos estudos, objetivos, método adotado e as principais conclusões de cada estudo, buscando identificar os fatores associados ao estresse e coping da equipe de Enfermagem de UTI.

Na etapa de análise dos dados ${ }^{19-20}$, eles foram organizados nas seguintes categorias de análise: 'Fatores estressantes da equipe de Enfermagem em UTI' e 'Coping da equipe de Enfermagem em UTI' - o objetivo desta etapa foi extrair o significado presente nos estudos selecionados e que possuíram adesão para responder ao problema de pesquisa proposto.

\section{RESULTADOS}

Entre as evidências referentes aos fatores estressantes, $46,7 \%$ (7) dos estudos mencionaram o 'cuidado à rede de apoio dos pacientes', assim como 46,7\% (7) referiram 'o lidar com a morte', considerados, portanto como os principais estressores da equipe de Enfermagem de UTI. Entre as demais evidências, o 'relacionamento interpessoal deficiente' (6) e o 'ambiente físico' (6) foram localizados igualmente em $40 \%$ dos artigos.

Quanto às evidências referentes ao coping da equipe de Enfermagem em UTI, houve destaque para o 'investimento nas relações interpessoais' (4), presente em 26,7\% dos estudos; e dos 'serviços de apoio disponibilizados pela liderança' (3), bem como do 'apoio fora do ambiente de trabalho' (3), ambos citados - cada um - em $20 \%$ dos estudos (Quadro 1). 
Quadro 1 - Características e evidências das publicações estudadas. São Paulo, 2019.

\begin{tabular}{|c|c|c|c|c|}
\hline \multirow{2}{*}{ Título } & \multirow{2}{*}{$\begin{array}{l}\text { Autores/ } \\
\text { Ano }\end{array}$} & \multirow{2}{*}{ Periódico } & \multicolumn{2}{|c|}{ Evidências } \\
\hline & & & $\begin{array}{l}\text { Referente aos fatores estressantes da } \\
\text { equipe de Enfermagem em UTI }\end{array}$ & $\begin{array}{l}\text { Referentes ao coping da } \\
\text { equipe de Enfermagem em UTI }\end{array}$ \\
\hline $\begin{array}{l}\text { Estresse e coping entre } \\
\text { profissionais de } \\
\text { enfermagem de Unidades de } \\
\text { Terapia Intensiva e Semi- } \\
\text { intensiva }\end{array}$ & $\begin{array}{l}\text { Silva et al, } \\
2017\end{array}$ & $\begin{array}{l}\text { Revista de } \\
\text { Enfermagem UFPE On } \\
\text { Line }\end{array}$ & $\begin{array}{l}\text { Desvalorização profissional } \\
\text { Poucas perspectivas de crescimento } \\
\text { Tempo insuficiente para realizar o trabalho } \\
\text { Inovações no ambiente hospitalar } \\
\text { Idade do profissional } \\
\text { Tempo de experiência }\end{array}$ & $\begin{array}{l}\text { Maior esforço e envolvimento no trabalho } \\
\text { Apoio social fora do trabalho } \\
\text { Lazer }\end{array}$ \\
\hline $\begin{array}{l}\text { O esgotamento dos } \\
\text { profissionais de } \\
\text { enfermagem: uma revisão } \\
\text { integrativa sobre a síndrome } \\
\text { de Burnout em UTI }\end{array}$ & $\begin{array}{l}\text { Machado } \\
\text { et al, } 2012\end{array}$ & $\begin{array}{l}\text { Revista de Pesquisa: } \\
\text { Cuidado é fundamental } \\
\text { Online }\end{array}$ & $\begin{array}{l}\text { Lidar com a morte } \\
\text { Cuidado à rede de apoio dos pacientes } \\
\text { Ambiente físico }\end{array}$ & - \\
\hline $\begin{array}{l}\text { Tensão no trabalho e a } \\
\text { prevalência de transtornos } \\
\text { mentais comuns entre } \\
\text { trabalhadores de } \\
\text { enfermagem }\end{array}$ & $\begin{array}{l}\text { Silva et al, } \\
2011\end{array}$ & $\begin{array}{l}\text { Revista de enfermagem } \\
\text { UFPE on line }\end{array}$ & $\begin{array}{l}\text { Lidar com a morte } \\
\text { Cuidado à rede de apoio dos pacientes Ambiente físico } \\
\text { Demandas psicológicas } \\
\text { Posição hierárquica do enfermeiro } \\
\text { Falta de recursos humanos } \\
\text { Carga horária de trabalho } \\
\text { Tempo insuficiente para realizar o trabalho } \\
\text { Indefinição do papel profissional } \\
\text { Insatisfação com o trabalho } \\
\text { Relacionamento interpessoal deficiente } \\
\text { Ambiente físico }\end{array}$ & - \\
\hline
\end{tabular}




\begin{tabular}{|c|c|c|c|c|}
\hline $\begin{array}{l}\text { Aspectos psicossociais e } \\
\text { síndrome de Burnout entre } \\
\text { trabalhadores de } \\
\text { Enfermagem intensivistas }\end{array}$ & $\begin{array}{l}\text { Lima, } \\
2015\end{array}$ & $\begin{array}{l}\text { Fundação Oswaldo } \\
\text { Cruz }\end{array}$ & $\begin{array}{l}\text { Carga horária de trabalho } \\
\text { Relacionamento interpessoal deficiente } \\
\text { Falta de recursos humanos } \\
\text { Sobrecarga de trabalho }\end{array}$ & - \\
\hline $\begin{array}{l}\text { O trabalho dos profissionais } \\
\text { de Enfermagem em } \\
\text { unidades de terapia } \\
\text { intensiva na assistência ao } \\
\text { paciente oncológico }\end{array}$ & $\begin{array}{l}\text { Hercos et } \\
\text { al, } 2014\end{array}$ & $\begin{array}{l}\text { Revista Brasileira de } \\
\text { Cancerologia }\end{array}$ & $\begin{array}{l}\text { Idade do profissional } \\
\text { Salário } \\
\text { Relacionamento interpessoal deficiente } \\
\text { Cuidado à rede de apoio dos pacientes } \\
\text { Lidar com a morte } \\
\text { Sobrecarga de trabalho } \\
\text { Duplas jornadas de trabalho } \\
\text { Ambiente físico }\end{array}$ & $\begin{array}{l}\text { Atividade física } \\
\text { Lazer } \\
\text { Uso da política de educação permanente } \\
\text { Serviços de apoio disponibilizados pela } \\
\text { liderança } \\
\text { Investimento na relação interpessoal no } \\
\text { trabalho }\end{array}$ \\
\hline $\begin{array}{l}\text { Prazer e sofrimento: } \\
\text { avaliação de enfermeiros } \\
\text { intensivistas à luz da } \\
\text { psicodinâmica do trabalho }\end{array}$ & $\begin{array}{l}\text { Campos et } \\
\text { al, } 2014\end{array}$ & $\begin{array}{l}\text { Escola Anna Nery } \\
\text { Revista de } \\
\text { Enfermagem }\end{array}$ & $\begin{array}{l}\text { Demandas psicológicas } \\
\text { Relacionamento interpessoal deficiente } \\
\text { Sobrecarga de trabalho } \\
\text { Tomada de decisão } \\
\text { Lidar com o sofrimento } \\
\text { Lidar com a morte } \\
\text { Preocupações com a segurança do paciente }\end{array}$ & $\begin{array}{l}\text { Investimento na relação interpessoal no } \\
\text { trabalho }\end{array}$ \\
\hline $\begin{array}{l}\text { Estresse dos profissionais } \\
\text { enfermeiros que atuam na } \\
\text { unidade de terapia intensiva }\end{array}$ & $\begin{array}{l}\text { Monte et } \\
\text { al, } 2013\end{array}$ & $\begin{array}{l}\text { Acta Paulista de } \\
\text { Enfermagem }\end{array}$ & $\begin{array}{l}\text { Tempo insuficiente para realizar o trabalho } \\
\text { Ambiente físico } \\
\text { Posição hierárquica do enfermeiro } \\
\text { Cuidado à rede de apoio dos pacientes } \\
\text { Lidar com o sofrimento } \\
\text { Lidar com a morte } \\
\text { Falta de recursos humanos } \\
\text { Falta de insumos } \\
\text { Frequentes situações de emergência } \\
\text { Controle de materiais usados e equipamentos }\end{array}$ & - \\
\hline
\end{tabular}




\begin{tabular}{|c|c|c|c|c|}
\hline $\begin{array}{l}\text { Avaliação do estresse e da } \\
\text { Síndrome de Burnout em } \\
\text { enfermeiros que atuam em } \\
\text { uma unidade de terapia } \\
\text { intensiva: um estudo } \\
\text { qualitativo }\end{array}$ & $\begin{array}{l}\text { Afecto; } \\
\text { Teixeira, } \\
2009\end{array}$ & $\begin{array}{l}\text { Online Brazilian } \\
\text { Journal of Nursing }\end{array}$ & $\begin{array}{l}\text { Esforço físico } \\
\text { Indefinição do papel profissional } \\
\text { Falta de recursos humanos } \\
\text { Ambiente físico } \\
\text { Turnos de trabalho } \\
\text { Dupla jornada de trabalho } \\
\text { Salário } \\
\text { Idade do profissional } \\
\text { Tempo de experiência } \\
\text { Sentimento de impotência diante das tarefas } \\
\text { Tempo insuficiente para realizar o trabalho } \\
\text { Resolver imprevistos } \\
\text { Posição hierárquica do enfermeiro }\end{array}$ & - \\
\hline $\begin{array}{l}\text { Estresse de enfermeiros com } \\
\text { atuação em Unidade de } \\
\text { Terapia Intensiva }\end{array}$ & $\begin{array}{l}\text { Cavalheiro } \\
\text { et al, } 2008\end{array}$ & $\begin{array}{l}\text { Rev Latino-Americana } \\
\text { de Enfermagem. }\end{array}$ & $\begin{array}{l}\text { Insatisfação com o trabalho } \\
\text { Turnos de trabalho } \\
\text { Relacionamento interpessoal deficiente } \\
\text { Sentimento de impotência diante das tarefas } \\
\text { Cuidado à rede de apoio dos pacientes } \\
\text { Assistência ao paciente grave }\end{array}$ & - \\
\hline $\begin{array}{l}\text { Grief and Burnout in the } \\
\text { PICU }\end{array}$ & $\begin{array}{l}\text { Crowe et } \\
\text { al, } 2017\end{array}$ & Pediatrics & - & Discutir casos desafiadores \\
\hline $\begin{array}{l}\text { Promoting staff } \\
\text { resilience in the pediatric } \\
\text { intensive care unit }\end{array}$ & $\begin{array}{l}\text { Jane Lee et } \\
\text { al, } 2015\end{array}$ & $\begin{array}{l}\text { American Journal of } \\
\text { Critical Care }\end{array}$ & $\begin{array}{l}\text { Dilemas éticos } \\
\text { Cuidado à rede de apoio dos pacientes } \\
\text { Lidar com o sofrimento } \\
\text { Lidar com a morte } \\
\text { Recursos limitados } \\
\text { Relacionamento interpessoal deficiente Preocupações } \\
\text { com a segurança do paciente }\end{array}$ & $\begin{array}{l}\text { Investimento na relação interpessoal no } \\
\text { trabalho } \\
\text { Apoio social fora do trabalho } \\
\text { Serviços de apoio disponibilizados pela } \\
\text { liderança }\end{array}$ \\
\hline
\end{tabular}




\begin{tabular}{|c|c|c|c|c|}
\hline $\begin{array}{l}\text { The prevalence of } \\
\text { compassion fatigue and } \\
\text { Burnout among healthcare } \\
\text { professionals in intensive } \\
\text { care units: a systematic } \\
\text { review }\end{array}$ & $\begin{array}{l}\text { Van Mol et } \\
\text { al, } 2015\end{array}$ & PLos One & & $\begin{array}{l}\text { Apoio dos superiores } \\
\text { Serviços de apoio disponibilizados pela } \\
\text { liderança } \\
\text { Meditação consciente }\end{array}$ \\
\hline $\begin{array}{l}\text { Burnout and traumatic stress } \\
\text { in staff working in } \\
\text { paediatric } \\
\text { intensive care: associations } \\
\text { with resilience and coping } \\
\text { strategies }\end{array}$ & $\begin{array}{l}\text { Colville et } \\
\text { al, } 2015\end{array}$ & $\begin{array}{l}\text { Intensive Care } \\
\text { Medicine }\end{array}$ & - & $\begin{array}{l}\text { Investimento na relação interpessoal no } \\
\text { trabalho } \\
\text { Apoio social fora do trabalho } \\
\text { Apoio dos superiores. }\end{array}$ \\
\hline $\begin{array}{l}\text { Ethical decision making in } \\
\text { intensive care units: a } \\
\text { Burnout risk factor? Results } \\
\text { from a multicentre study } \\
\text { conducted with physicians } \\
\text { and nurses }\end{array}$ & $\begin{array}{l}\text { Teixeira et } \\
\text { al, } 2014\end{array}$ & $\begin{array}{l}\text { Journal of Medical } \\
\text { Ethics }\end{array}$ & $\begin{array}{l}\text { Lidar com a morte } \\
\text { Cuidado à rede de apoio dos pacientes }\end{array}$ & $\begin{array}{l}\text { Envolvimento dos enfermeiros no processo } \\
\text { de tomada de decisão }\end{array}$ \\
\hline $\begin{array}{l}\text { Estudo preliminar sobre o } \\
\text { estresse ocupacional de } \\
\text { médicos e } \\
\text { enfermeiros em UTI } \\
\text { pediátrica e neonatal: o } \\
\text { equilíbrio entre esforço e } \\
\text { recompensa }\end{array}$ & $\begin{array}{l}\text { Fogaça et } \\
\text { al, } 2010\end{array}$ & $\begin{array}{l}\text { Revista Latino- } \\
\text { Americana de } \\
\text { Enfermagem }\end{array}$ & Desvalorização profissional & - \\
\hline
\end{tabular}




\section{DISCUSSÃO}

Entre os estressores mencionados, o 'cuidado à rede de apoio dos pacientes' e 'lidar com a morte' receberam destaque pelos profissionais participantes dos estudos selecionados. Embora seja o ambiente ideal para $\mathrm{o}$ atendimento a pacientes graves, a UTI gera um estresse muito grande sobre a equipe de Enfermagem, porque além de lidar com situações de morte e de vida do paciente, a equipe lida com os sentimentos dos familiares e, também, com suas próprias emoções e conflitos - isto denota o que Dejours (1992) argumenta ao considerar que não é possível a separação do ser humano do ser profissional, o que - em última análise - impõe aos estabelecimentos de saúde a necessidade de adoção de medidas que consigam responder à complexidade do ser enfermeiro em UTI. 7

Isto ficou evidente em Monte et al (2013), que referiu que entre os principais fatores relacionados ao estresse na equipe de saúde e presentes no ambiente de cuidados intensivos há a necessidade do preparo para lidar com a morte e o sofrimento. ${ }^{21}$

Assim, vivenciar a morte e os sentimentos da rede de apoio dos pacientes frente ao seu estado de saúde é condição inerente aos profissionais da UTI submetendo-os a um processo de trabalho multidimensional que exige diferentes competências, entre as quais, as emocionais, o que denota a necessidade da existência de um suporte para discussões.

Tal suporte foi mencionado nas evidências deste estudo, como estratégia de coping, em que os profissionais sugeriram a existência de apoio psicológico sistematizado aos profissionais para $o$ enfrentamento das dificuldades no seu cotidiano de trabalho, assim como de outros serviços de apoio disponibilizados pela liderança, proporcionando discussões a respeito de cuidados espirituais, serviço social, cuidados paliativos, dilemas éticos e psicologia, além da discussão de casos desafiadores, preparo dos profissionais para lidar com a morte e com a família - sua ansiedade, seus medos e possível descontrole frente ao processo de saúdedoença.

Esta proposta é consonante aos achados de Silva (2000), que referiu a necessidade de os profissionais atuantes em UTI criarem um bom relacionamento com a família, facilitando sua participação no tratamento do paciente, de modo a preparála e acompanhá-la durante todo o processo 
de internação, identificando e esclarecendo suas dúvidas, observando as reações e comportamentos e, especialmente, compreendendo seus sentimentos..$^{22-23}$

A literatura aponta que conflitos nas relações interpessoais são uma das fontes de estresse de maior importância. ${ }^{24-25}$ Leite e Vila (2005) discutiram que um dos principais fatores causadores de estresse para a equipe multiprofissional é a própria equipe, fato justificado pela falta de compromisso de alguns de seus membros, intervindo negativamente na qualidade da assistência ao paciente. Esta evidência dialoga diretamente com os resultados deste estudo, que apontaram este aspecto como estressante na equipe de Enfermagem, o que aponta para a pertinência de ações direcionadas para a mediação destes conflitos, através do apoio social no ambiente de trabalho, estimulando um bom relacionamento entre a equipe, diálogos construtivos e reflexão entre os colegas, valorizando a honestidade, estabelecendo respeito entre as partes e motivando o comprometimento com a assistência. ${ }^{23}$

Quanto ao investimento nas relações interpessoais, encontrado como evidência relacionada ao coping neste estudo, Formozo (2012) afirma que é primordial no desenvolvimento do cuidado com vistas à fortalecer a humanização, contemplando elementos como a empatia e a escuta ativa. $^{26}$

Diante disso, destaca-se a necessidade de constante capacitação dos profissionais, para além de procedimentos técnicos, ou seja, que também se preocupem com a capacitação profisssional para o lidar com o processo de morte ${ }^{26}$. Conforme as evidências deste estudo, tal capacitação deve ser realizada através do 'uso da política de educação permanente', a qual contribui para a atualização dos conhecimentos e permite a quebra da rotina ocupacional, promovendo a adaptação do indivíduo para um melhor enfrentamento das situações do dia a dia, melhorando sua autoestima e o subsidiando para lidar com o estresse. $^{27,28}$

O ambiente de trabalho de UTI é estressante, as atividades desenvolvidas exigem profuso grau de responsabilidade e qualificação, envolvendo desgaste emocional intenso. ${ }^{29}$ Além disso, o ambiente físico envolve fatores como a iluminação e ventilação inadequadas, barulho excessivo e escassez de recursos materiais, constatados nos resultados trazidos por Coronett et al (2006). ${ }^{27}$ Esses fatores estressantes foram encontrados, igualmente, neste estudo - quando denotado, no ambiente físico, algumas medidas protetivas importantes da rotina de trabalho e que podem ser realizadas, como: 
evitar o barulho causado pelo diálogo em voz alta próximo aos pacientes, discussões clínicas realizadas em ambientes próprios, redução dos sons de alarme dos equipamentos sempre que possível, controle de campainhas, alarmes e celulares, além da implementação de um programa de educação continuada alinhado para o desenvolvimento de ações direcionadas para os aspectos interrelacionais e emocionais. ${ }^{30}$

No que se refere à atuação do enfermeiro, ressalta-se que ele desempenha muitas atividades com alto grau de dificuldade e responsabilidade, sendo considerado o mediador entre a equipe de Enfermagem, a equipe multidisciplinar, o paciente assistido e sua família, buscando o equilíbrio entre as relações desenvolvidas, o que pode gerar estresse. ${ }^{31}$ Nos artigos analisados neste estudo, foi possível identificar o quanto 'ser enfermeiro' se relaciona ao estresse, como por exemplo, ao considerar a desvalorização profissional, a reduzida perspectiva de crescimento, as inovações tecnológicas contínuas, a idade do profissional, o tempo de experiência, a necessidade de tomada de decisão, a posição hierárquica do enfermeiro, a responsabilidade sobre o controle de materiais e equipamentos, o lidar com imprevistos e a insatisfação com o trabalho.
O apoio social pode ser definido como qualquer informação, assistência material e proteção oferecida por grupos sociais e/ou instituições, como a família e trabalho coletivo, e que resultem em efeitos emocionais positivos. ${ }^{32}$ Entre as evidências encontradas referentes ao coping da equipe de Enfermagem em UTI, foi possível destacar o apoio social como principal estratégia utilizada, esteja ela presente no ambiente de trabalho, na instituição, liderança ou entre os colegas, ou mesmo fora do trabalho, com a família, o contato com amigos, entre outros. De tal modo, ao se tratar do 'apoio social no ambiente de trabalho', o papel da liderança aparece como primordial, estimula o trabalho conjunto, favorece o trabalho multidisciplinar, e minimiza o efeito decorrente do estresse. ${ }^{33}$ Theorell (2000) defende que na relação entre demandas psicológicas e controle no trabalho, o apoio de colegas de trabalho e da própria instituição pode funcionar como uma ação protetiva ao estresse. ${ }^{34}$

Dentre os artigos analisados, o 'apoio social fora do ambiente de trabalho' foi relacionado às interações sociais informais, e à prática de atividade física e de lazer. Segundo Pereira e Bueno (1997), o lazer tem papel essencial, enquanto meio alternativo para o relaxamento e o alívio das 
dificuldades do dia a dia, seja no nível pessoal ou profissional. ${ }^{35}$

Quanto às limitações do estudo, foi possível constatar que inúmeros são os fatores estressantes para a equipe de Enfermagem em UTI, mas pouco se fala sobre as estratégias de coping, e se há conhecimento do profissional a respeito de sua importância, o que denota a necessidade de novos estudos com este tipo de direcionamento.

Portanto, entre as suas responsabilidades, o enfermeiro deverá avaliar o ambiente e os profissionais na rotina do setor, investigar a presença de fatores causadores de estresse, respeitando a individualidade de cada membro da equipe, e agir de modo a proporcionar ambiente favorável e acesso a redes de apoio disponíveis, visando potencializar as estratégias de coping e o controle do estresse.

\section{CONSIDERAÇÕES FINAIS}

A equipe de Enfermagem de UTI desenvolve seu trabalho em um ambiente de inúmeras demandas, tanto físicas, como mentais, as quais são impostas ao profissional e são peculiares ao setor de UTI, o que contribui para o estabelecimento do estresse - como ficou evidente neste estudo ao identificar que entre os fatores estressantes da equipe de Enfermagem em
UTI destacaram-se, principalmente, o 'cuidado à rede de apoio dos pacientes' e o 'lidar com a morte.'

Assim, o estresse em resposta a tantas demandas exigidas pelo trabalho na UTI deve ser potencialmente investigado, e o estabelecimento de ações que visem solucionar ou minimizar os seus efeitos são primordiais.

Em relação ao coping da equipe de Enfermagem em UTI, poucas estratégias foram mencionadas denotando a limitação deste estudo. Entretanto, destacou-se o 'investimento nas relações interpessoais', uso dos 'serviços de apoio disponibilizados pela liderança' e 'apoio fora do ambiente de trabalho' - através de interações sociais informais, atividade física e lazer - o que contribui para um ambiente de trabalho seguro e que proporciona bem-estar e, por conseguinte, garante a segurança do cuidado prestado ao paciente, o suporte a sua rede de apoio e, em última análise, a qualidade do cuidado.

\section{REFERÊNCIAS}

1. Ministério da Saúde (Brasil). Doenças relacionadas ao trabalho: manual de procedimentos para os serviços de saúde. Brasília, DF: Ministério da Saúde; 2001.

2. Organisation Mondiale de la Santé. Identificación de enfermedades relacionadas com el trabayo y medidas para combatirlas. Genebra: OMS; 1985. 
3. Stacciarini JMR, Tróccoli BT. The stress in nursing profession. Rev Latinoam Enferm. 2001; 9(2):17-25.

4. Inouel KC, Versa GLG, Murassaki ACY, Melo WA, Matsuda LM. Estresse ocupacional em enfermeiros intensivistas que prestam cuidados diretos ao paciente crítico. Rev Bras Enferm. 2013; 66(5):72229.

5. Fogaça MC, Carvalho WB, Citero VA, Martins LAN. Fatores que tornam estressante o trabalho de médicos e enfermeiros em terapia intensiva pediátrica e neonatal: estudo de revisão bibliográfica. Rev Bras Ter Intensiva. 2008; 20(3):26166.

6. Vieira LC, Guimarães LAM, Martins DA. Saúde mental e trabalho. 3ed. São Paulo: Casa do Psicólogo; 2003. 7. Dejours C. A loucura do trabalho: estudo de psicopatologia do trabalho. 5ed. São Paulo: Cortez; 1992.

8. Carvalho DV, Lima FCA, Costa TMPF, Paula Lima EDR. Enfermagem em setor fechado - estresse ocupacional. Reme Rev Min Enferm. 2004; 8(2):290-94. 9. Lazarus RS, Launier S. Stress related transaction between person and enviroment. In: Dervin LA, Lewis M. Perspectives in international psychology. New York: Plenum; 1978. p. 287-327. 10. Andolhe R, Barbosa RL, Oliveira EM, Costa ALS, Padilha KG. Estresse, coping e burnout da Equipe de enfermagem de unidades de terapia intensiva: fatores associados. Rev Esc Enferm USP. 2015; 49(N. Esp):58-64. 11. Figueiras JC, Hippert MIS. A polêmica em torno do conceito de estresse. Psicol Ciênc Prof. 1999; 19(3):4051.

12. Malagrias LEN, Fiorito ACC. Avaliação do nível de stress de técnicos da área de saúde. Estud Psicol. (Campinas). $2006 \mathrm{dez} ; 23(4): 391-98$.

13. Menzies IEP. Nurses under stress. Int Nurs Rev. 1960; 7(6):9-16.

14. McCarthy VJC, Power S, Greiner BA. Perceived occupational stress in nurses working in Ireland. Occup Med. 2010; 60(8):604-10.

15. Silva GAV, Silva GSA, Silva RM, Andolhe R, Padilha KG, Costa ALS.

Estresse e coping entre profissionais de enfermagem de unidades de terapia intensiva e semi-intensiva. Rev Enferm UFPE on line. [Internet]. 2017 [citado em 23 jan 2019]; 11(Supl 2):922-31.

Disponível em: https://periodicos.ufpe.br/revistas/revistaen fermagem/article/view/13461/16153

16. Rodrigues AB, Chaves EC. Fatores estressantes e estratégias de coping dos enfermeiros atuantes em oncologia. Rev Latinoam Enferm. 2008; 16(1):1-5.

17. Souza MT, Silva MD, Carvalho R. Revisão integrativa: o que é e como fazer. Einstein. 2010; 8(1):102-6.

18. Jensen R, Lopes MHBM.

Enfermagem e lógica fuzzy: uma revisão integrativa. Rev Latinoam Enferm. 2011; 19(1):1-8.

19. Whittemore R, Knafl K. The integrative review: updated methodology. J Adv Nurs. 2005; 52(5):546-53.

20. Cooper H. Synthesizing research: a guide for literature reviews: Thousand Oaks, CA: Sage Publications; 1998.

21. Monte PF, Lima FET, Neves FMO, Studart RMB, Dantas RT. Stress among professional nurses working in intensive care units. Acta Paul Enferm. [Internet]. 2013 [citado em 23 jan 2019]; 26(5):42127. Disponível em: http://www.scielo.br/pdf/ape/v26n5/en_a0 4v26n5.pdf

22. Silva MJP. Humanização em UTI. In: Cintra EA, Nishide VM, Nunes WA. Assistência de enfermagem ao paciente crítico. São Paulo: Atheneu; 2000. p. 1-11. 23. Leite MA, Vila VSC. Dificuldades vivenciadas pela equipe multiprofissional na unidade de terapia intensiva. Rev Latinoam Enferm. 2005; 13(2):145-50. 24. Stacciarini JMR, Tróccolli BT. Estresse ocupacional. In: Mendes AM, Borges LO, Ferreira MC, organizadores. 
Trabalho em transição, saúde em risco. Brasília, DF: Ed. UnB; 2002. p. 25-42. 25. Farias SNP, Mauro MYC, Zeitoune RCG. Questões Legais sobre a saúde do trabalhador de enfermagem. Rev Enferm UERJ. 2000; 8(1):28-32.

26. Formozo GA, Oliveira DC, Costa

TL, Gomes AMT. As relações interpessoais no cuidado em saúde: uma aproximação ao problema. Rev Enferm UERJ. 2012; 20(1):124-27.

27. Coronetti A, Nascimento ERP, Barra DCC, Martins JJ. O estresse da equipe de enfermagem na unidade de terapia intensiva: o enfermeiro como mediador. ACM Arq Catarin Med. 2006; 35(4):36-43.

28. Schwartz S. O estresse e como viver com ele: implicações para a prática de enfermagem. In: Shumaker WC. Tratado de terapia intensiva. São Paulo: Panamericana; 1992. p. 1413-16.

29. Ferrareze, MVG, Ferreira, V, Carvalho, AMP. Percepção do estresse entre enfermeiros que atuam em Terapia Intensiva. Acta Paul Enferm. 2006; 19(3):310-15.

30. Macedo ISC, Mateus DC, Costa EMGC, Asprino ACL, Lourenço E. Avaliação do ruído em unidades de terapia intensiva. Braz J Otorhinolaryngol. 2009; 75(6):844-46.

31. Ferreira LRC, Martino MMF. O estresse do enfermeiro. Rev Ciênc Méd., (Campinas). 2006; 15(3):241-48.

32. Gonçalves TR, Pawlowski J,

Bandeira DR, Piccinini CA. Avaliação de apoio social em estudos brasileiros: aspectos conceituais e instrumentos. Ciênc Saúde Colet. 2011; 16(3):1755-69.

33. Reis ALPP, Fernandes SRP, Gomes AF. Estresse e fatores psicossociais. Psicol Cienc Prof. 2010; 30(4):712-25.

34. Theorell T. Working conditions and health. In: Berkman L, Kawachi I. Social epidemiology. New York: Oxford University Press; 2000. p. 484-493.

35. Pereira MER, Bueno SMV. Lazer Um caminho para aliviar as tensões no ambiente de trabalho em UTI: uma concepção da equipe de enfermagem. Rev Latinoam Enferm. 1997; 5(4):75-83.

RECEBIDO: 04/09/2018

APROVADO: $17 / 02 / 2019$

PUBLICADO: $12 / 2019$ 